\title{
BENEDITO E O PERFIL DE UM POLÍTICO: UMA IRÔNICA "EVOLUÇÃO"
}

\section{ADRIANA DA COSTA TELES}

Universidade de São Paulo/FAPESP

São Paulo, São Paulo, Brasil

Resumo: O presente artigo discute o conto "Evolução", publicado por Machado de Assis na Gazeta de Notícias, no ano de 1884, e mais tarde recolhido em Relíquias de casa velha, editado em 1906. A leitura aqui apresentada parte da ideia de que o texto, em temática bastante apropriada ao veículo que o fez circular, deixa ver uma discussão sobre práticas políticas no Brasil da época, que surgem problematizadas pelo olhar irônico e crítico do autor.

Palavras-chave: Machado de Assis; conto; "Evolução".

\section{BENEDITO AND THE PROFILE OF A POLITICIAN:} AN IRONIC "EVOLUTION"

Abstract: This article aims at discussing the short story "Evolução", published by Machado de Assis in the newspaper Gazeta de Notícias, in 1884, and later in the book Relíquias de casa velha, in 1906. Our interpretation stems from the idea that the text, written with a suitable theme for this newspaper, shows a discussion about political practices in Brazil at that time, with the ironic and critical eye of the author.

Keywords: Machado de Assis; short story; "Evolução".

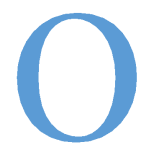

conto "Evolução" foi originalmente publicado por Machado de Assis em 24 de junho de 1884, na Gazeta de Notícias. Recolhido, anos mais tarde, em Reliquias de casa velha (1906), a narrativa ajuda a compor aquela que é tida como fase madura do escritor brasileiro. A história, que trata de dois conhecidos às voltas com questões políticas e do desenvolvimento do Brasil, tem tema bastante apropriado ao público leitor da Gazeta, jornal de perfil liberal e politicamente independente, disposto a acolher boas produções literárias, e veículo no qual Machado publicou seus contos mais memoráveis. "Evolução" 
afasta-se, desse modo, das narrativas de cunho romanesco que o autor produzia para $A$ Estação, no mesmo período, e que caracterizam parte expressiva de sua produção no gênero, pelo menos até aquele momento.

O conto nos coloca em contato com Benedito e Inácio e nos leva a acompanhar, por meio da narração do último, a "evolução" que tem uma conversa ocorrida entre ele e um recém-conhecido, em viagem para Vassouras, anos antes do momento da enunciação narrativa. Na ocasião, a convivência forçada pelo percurso os leva a conversar e o assunto que naturalmente surge é o das estradas de ferro, um avanço inquestionável nas condições da viagem, antes realizada em lombo de burro. $\mathrm{Na}$ ocasião, Inácio compara "o Brasil a uma criança que está engatinhando; só começará a andar quando tiver muitas estradas de ferro". ${ }^{1}$ Benedito, que acha "bonita ideia" a do companheiro, retoma a frase poucas semanas depois, quando reencontra Inácio no Rio de Janeiro: "o que o senhor dizia na diligência". ${ }^{2}$ A fala de Inácio passa, a partir de então, a compor gradativamente o discurso de seu interlocutor. "O senhor dizia" se transforma em "nós", em Paris, tempos depois, onde Inácio se encontrava a trabalho e Benedito passeava depois de ter perdido a eleição para deputado: "Lembra-se do que nós dizíamos na diligência [...]". ${ }^{3}$ Para espanto de Inácio, anos mais tarde, no Rio, sua frase se encontra definitivamente de posse de Benedito, que, eleito deputado, lê para o narrador o discurso que faria na câmara: "[...] e aqui repetirei o que, há alguns anos, dizia eu a um amigo, em viagem pelo interior: o Brasil é uma criança que engatinha; só começará a andar quando estiver cortado de estradas de ferro...". ${ }^{4} \mathrm{O}$ conto termina com uma reflexão do narrador, que, espantado, percebe que Benedito parecia acreditar no que dizia:

Não pude ouvir mais nada e fiquei pensativo. [...] Este homem é sincero, pensei comigo, está persuadido do que escreveu. E fui por aí abaixo até ver se achava a explicação dos trâmites por que passou aquela recordação da diligência de Vassouras. Achei (perdoem-me se há nisto enfatuação), achei

1 ASSIS, Contos: uma antologia, vol. 2, p. 203.

2 Ibidem, grifo do autor.

3 Idem, p. 205, grifo do autor.

4 Idem, p. 207, grifo do autor. 
ali mais um efeito da lei da evolução, tal como a definiu Spencer, - Spencer ou Benedito, um deles. ${ }^{5}$

Em um primeiro momento, a narrativa parece discutir a "evolução" da apropriação do discurso de Inácio por Benedito, que intriga o narrador e é, aparentemente, o que o motiva ao relato. Em consonância com a teoria de Spencer, Alfredo Bosi afirma, ao abordar o conto, em "A máscara e a fenda": "Evolução é uma apropriação bem-sucedida. O resultado final chama-se posse. Assim na História como na Natureza. O fato de ser uma ideia, uma frase, uma simples metáfora, o objeto da apropriação apenas refina o projeto de autoconservação". ${ }^{6}$ Seja na natureza ou na sociedade, o ser busca sua própria preservação, que encontra, entre os homens civilizados e cultos, meios e objetos, por vezes, mais refinados e sofisticados.

Deve ser notado, no entanto, que, concomitantemente à apropriação do discurso de Inácio por Benedito, o conto delineia o perfil de um homem da elite brasileira do século XIX, que se torna um político. Observado por esse prisma, o conto deixa ver vários processos que envolvem mudanças, ao longo de sua história: o discurso de Inácio que passa a ser de Benedito; Benedito, que, de homem rico, agrega à sua posição o cargo de deputado; e o próprio narrador, que presencia o seu discurso se transformar no do amigo. A "evolução", que o título anuncia, tomada em sentido amplo, é, assim, relevante no conto, espécie de leitmotiv que paira sobre toda a história, uma vez que há vários "processos evolutivos" em jogo.

O desenrolar de todas essas questões gira em torno de Benedito, o que torna o estudo do personagem de fundamental importância para a discussão da história. Mas, primeiramente, deve ser observado que a proposta do narrador assinala a preocupação em discutir um "tipo moral", mais do que um personagem individualizado. O dado é perceptível já no início da narrativa e deve ser considerado com atenção. A citação de Romeu e Julieta, que domina o primeiro e o segundo parágrafos do texto, aponta justamente para essa questão, funcionando como uma espécie de mote para a história que leremos. Acompanhemos:

5 Ibidem.

6 BOSI, O enigma do olhar, p. 119. 
Chamo-me Inácio; ele, Benedito. Não digo o resto dos nossos nomes por um sentimento de compostura, que toda a gente discreta apreciará. Inácio basta. Contentem-se com Benedito. Não é muito, mas é alguma coisa, e está com a filosofia de Julieta: "Que valem nomes? perguntava ela ao namorado. A rosa, como quer que se lhe chame, terá sempre o mesmo cheiro". Vamos ao cheiro do Benedito. ${ }^{7}$

A famosa pergunta de Julieta coloca nomes em segundo plano para privilegiar o ser em sua essência. O convite do narrador está de acordo com essa filosofia. Os nomes são o que menos interessa, nesse conto. Inácio e Benedito bastam para que ele aborde a pessoa moral do conhecido. A expressão "Vamos ao cheiro do Benedito" chama o leitor para que observe de perto aquele homem. Para além da apropriação da ideia de Inácio, portanto, o que está em jogo é um determinado padrão de comportamento moral que Benedito demonstra - o "cheiro" dessa rosa -, em contraposição a outras "flores" do "jardim social".

$\mathrm{Na}$ sequência, Inácio nos adianta, dando continuidade ao paralelo que traça com a tragédia, que Benedito se distancia do personagem shakespeariano: "E desde logo assentemos que ele era o menos Romeu deste mundo. Tinha quarenta e cinco anos, quando o conheci; não declaro em que tempo, porque tudo neste conto há de ser misterioso e truncado". ${ }^{8}$ A diferença entre Romeu e Benedito, no entanto, não fica apenas por conta da idade. A comparação expõe ao leitor a ausência de traços heroicos ou romanescos do amigo de Inácio. Deve ser observada com atenção a descrição que o narrador faz da aparência de Benedito, na sequência, que não apenas corrobora essa primeira característica do personagem, como deixa ver dados importantes de sua personalidade:

Quarenta e cinco anos, e muitos cabelos pretos; para os que o não eram usava um processo químico, tão eficaz que não se lhe distinguiam os pretos dos outros - salvo ao levantar da cama; mas ao levantar da cama não aparecia a ninguém. Tudo mais era natural, pernas, braços, cabeça, olhos, roupa, sapatos, corrente do relógio e bengala. O próprio alfinete de diamante, que trazia na gravata, um dos mais lindos que tenho visto, era

7 ASSIS, cit., p. 201.

8 Ibidem. 
natural e legítimo, custou-lhe bom dinheiro; eu mesmo o vi comprar na casa do... lá me ia escapando o nome do joalheiro; - fiquemos na rua do Ouvidor ${ }^{9}$.

Como vemos, quase tudo era natural em Benedito. O destaque é dado a um belo alfinete de diamante que ele trazia na gravata, comprado de um joalheiro cujo nome o narrador não revela; afinal, trata-se de uma história em que nomes pouco importam. Importa, por outro lado, a autenticidade da aparência do personagem, que Inácio afirma ser quebrada unicamente pelos cabelos brancos que ele tingia de pretos, por meio de um processo químico. Ou seja: a única coisa pouco natural em Benedito está justamente na artificialidade que lhe recobre a cabeça... Os fios naturais e sem cor ficam reservados para a sua intimidade; para o público surgem travestidos e ajudam a compor um visual que parece primar todo ele pela originalidade.

O caráter pacato e a pouca autenticidade intelectual do amigo são reconhecidos, na sequência, pelo narrador, que aproveita para assinalar o pensamento eclético do personagem, em que tudo convive e se concilia, sem dramas ou embates:

Ninguém muda de caráter, e o Benedito era bom, - ou para melhor dizer, pacato. Mas, intelectualmente, é que ele era menos original. Podemos compará-lo a uma hospedaria bem afreguesada, aonde iam ter ideias de toda parte e de toda sorte, que se sentavam à mesa com a família da casa. Às vezes, acontecia acharem-se ali duas pessoas inimigas, ou simplesmente antipáticas; ninguém brigava, o dono da casa impunha aos hóspedes a indulgência recíproca. ${ }^{10}$

O comportamento e o discurso do personagem, descritos ao longo da narrativa, são bastante coerentes com a descrição que o narrador faz de sua pessoa, no início da narração. Primeiramente, observamos que a aparência perfeita, finalizada pelo diamante bonito e caro, se espelha em seu discurso: Benedito era um sujeito que gostava de ideias e frases impactantes, que produziam certo efeito. O dado é perceptível ao longo de todo o texto e já se

9 Ibidem.

10 Idem, p. 201-202. 
anuncia no diálogo que trava com Inácio na referida viagem a Vassouras, que dá origem à história:

- [... Eu comparo o Brasil a uma criança que está engatinhando; só começará a andar quando tiver muitas estradas de ferro.

- Bonita ideia! - exclamou Benedito faiscando-lhe os olhos.

- Importa-me pouco que seja bonita, contanto que seja justa.

- Bonita e justa - redarguiu ele com amabilidade. ${ }^{11}$

Para Benedito, "justa" é uma qualidade que vem depois da suposta beleza da expressão proferida pelo companheiro. Deve ser observado que o personagem concorda com o narrador para ser amável; ele não absorve a sua fala enquanto ideia realmente válida, mas como algo bonito de ser dito. Desse modo, o que atrai Benedito é a capacidade oratória da frase; ela impressiona (como o diamante que carrega na gravata) e isso faz seus olhos faiscarem.

Essa postura, que privilegia a roupagem e o adorno, é perceptível em tudo o que rodeia o personagem. Na passagem abaixo, por exemplo, Inácio visita o amigo e assim nos descreve a conversa que tiveram:

E referiu muita coisa, observações relativas aos costumes do interior, dificuldades da vida, atraso, concordando, porém, nos bons sentimentos da população e nas aspirações de progresso. Infelizmente, o governo não correspondia às necessidades da pátria; parecia até interessado em mantêla atrás das outras nações americanas. Mas era indispensável que nos persuadíssemos de que os princípios são tudo e os homens nada. Não se fazem os povos para os governos, mas os governos para os povos; e abyssus abyssum invocat. ${ }^{12}$

Em política, Benedito mostra ideias progressistas e liberais, em contraposição ao governo, que emperrava o desenvolvimento do país e não atendia às necessidades da pátria. No entanto, suas belas falas - "os princípios são tudo e os homens nada"; "não se fazem os povos para os governos, mas os governos para os povos" - reproduzem ideias que beiram o lugar comum; frases

11 Idem, p. 202-203.

12 Idem, p. 203, grifo do autor. 
de efeito amplamente repetidas, que, por fim, se esvaziam de seus conteúdos originais e, desse modo, apenas integram um determinado perfil de discurso. A expressão latina que Inácio acrescenta à sua narração, abyssus abyssum invocat, e que John Gledson, em nota à coletânea citada ao longo deste artigo, traduz como "uma desgraça leva a outra", ${ }^{13}$ fomenta a ideia de um ciclo interminável, seja de problemas ou de discursos sobre eles.

A cena acima tem continuidade quando Benedito mostra ao narrador algumas das salas de sua casa: "Eram todas alfaiadas com apuro. Mostrou-me as coleções de quadros, de moedas, de livros antigos, de selos, de armas; tinha espadas e floretes, mas confessou que não sabia esgrimir". ${ }^{14}$ Suas coleções se sucedem e ornamentam os ambientes com acúmulos que denotam apreço à cultura e ao conhecimento. No entanto, elas servem, nos dizeres do narrador, para "alfaiar" o espaço, e, enquanto tal, valem para pouco. O detalhe das espadas e floretes é significativo: Benedito nem sabe esgrimir. O futuro deputado é nitidamente afastado de questões práticas. Até mesmo o livro aberto com aparente displicência em cima da rica escrivaninha parece parte de um cenário: "A secretária era de ébano, obra fina; sobre ela casualmente aberto, um almanaque de Laemmert". ${ }^{15} \mathrm{O}$ Almanaque administrativo, mercantil e industrial da Corte do Rio de Janeiro, que veiculava anualmente dados estatísticos sobre o país, parece ele também ornamento, que alfaia o ambiente, e está ali para causar certa impressão, seja isso consciente ou não, por parte do personagem.

A ideia de entrar para a política veio por sugestão do próprio narrador: "[...] queria ser deputado. Fui eu mesmo que o induzi a isso, sem a menor intenção política, mas com o único fim de lhe ser agradável; mal comparando, era como se lhe elogiasse o corte do colete. Ele pegou da ideia, e apresentou-se". ${ }^{16}$ Mais do que uma vocação para a política, portanto, ser deputado é uma ideia que surge por contingência, na vida de Benedito. Uma sugestão que se casa a uma espécie de caminho natural para alguém de sua posição e nível social. Aliás, apesar de ter se dado com o fim de "lhe ser agradável" não seria esse, afinal, o motivo que teria levado Inácio a sugerir a candidatura ao amigo?

13 Ibidem.

14 Idem, p. 203-204.

15 Idem, p. 204.

16 Idem, p. 204-205.

Machado de Assis em linha, Rio de Janeiro. v. 7, n. 14, p. 198-208, dezembro 2014 Fundação Casa de Rui Barbosa - R. São Clemente, 134, Botafogo - 22260-000 - Rio de Janeiro, RJ, Brasil 
Na ocasião em que Inácio encontra Benedito em Paris, ficamos sabendo que o motivo que levara o narrador até lá era justamente a construção de uma estrada de ferro. Nessa ocasião, ele mostra dados do projeto para o amigo, que, em princípio, se encanta com o que vê e chega a buscar ele próprio informações que pudesse levar para o Brasil:

Mostrei-lhe os papéis, ele viu-os deslumbrado. Como eu tivesse então recolhido alguns apontamentos, dados estatísticos, folhetos, relatórios, cópias de contratos, tudo referente a matérias industriais, e lhos mostrasse, Benedito declarou-me que ia também coligir algumas coisas daquelas. E, na verdade, vi-o andar por ministérios, bancos, associações, pedindo muitas notas e opúsculos, que amontoava nas malas [...]. ${ }^{17}$

Mas, esse empenho todo (que serve para encher malas) é passageiro: "o ardor com que o fez, se foi intenso, foi curto; era de empréstimo". ${ }^{18}$ Benedito parece reconhecer a importância dos apontamentos mostrados pelo amigo, mas eles não o seduzem, de fato; a empolgação é emprestada de Inácio, como ele próprio sugere em sua narração. Em contrapartida, ao final de algum tempo, vemos o futuro deputado completamente seduzido pela vida parlamentar europeia, o que é descrito na sequência:

Benedito recolheu com muito mais gosto os anexins políticos e fórmulas parlamentares. Tinha na cabeça um vasto arsenal deles. Nas conversas comigo repetia-os muita vez, à laia de experiência; achava neles grande prestígio e valor inestimável. Muitos eram de tradição inglesa, e ele os preferia aos outros, como trazendo em si um pouco da Câmara dos Comuns. Saboreava-os tanto que eu não sei se ele aceitaria jamais a liberdade real sem aquele aparelho verbal; creio que não. Creio até que, se tivesse de optar, optaria por essas formas curtas, tão cômodas, algumas lindas, outras sonoras, todas axiomáticas, que não forçam a reflexão, preenchem os vazios, e deixam a gente em paz com Deus e os homens. ${ }^{19}$

17 Idem, p. 205.

18 Ibidem.

19 Idem, p. 206-207. 
Benedito aprecia pompas e discursos superficiais e inflados em detrimento de atitudes que possam produzir, de fato, alguma mudança. Trata-se de uma postura que é coerente com outros aspectos de sua pessoa. As expressões sonoras e axiomáticas que cultiva guardam semelhança com as coleções de livros antigos, selos, moedas e armas, que tinha em casa, e com o diamante que ostenta na gravata. Tudo serve, afinal, para preencher vazios, máscaras de um grande oco.

É relevante que retomemos, mais uma vez, as reflexões de Alfredo Bosi. Em artigo já citado, aqui, o crítico evoca o conto "Teoria do medalhão", publicado por Machado em dezembro de 1881, também na Gazeta de Notícias, ao discorrer sobre "Evolução". Para Bosi, o que lemos nessa narrativa machadiana tardia é o próprio medalhão em ato. Acompanhamos, por meio da narração de Inácio, um sujeito "na idade justa dos quarenta e cinco anos, disposto a repetir todos os lugares-comuns do mundo e a fazer uma sólida carreira de deputado sem ideias". ${ }^{20}$

A discussão empreendida até aqui mostra justamente que a subtração da fala de Inácio por parte de Benedito é apenas um detalhe em meio a um comportamento maior, que privilegia o empréstimo de ideias alheias na confecção de certa retórica. O fenômeno torna-se ainda mais interessante quando nos atemos a um detalhe que intriga o narrador: Benedito estava convencido de que era ele quem havia tido a ideia sobre o Brasil engatinhando. Ou seja, ele parece acreditar que é alguém que tem projetos e ideias boas e promissoras. No entanto, o narrador e o leitor sabem que isso não é verdade, afinal seus belos pensamentos são incorporados ao seu discurso enquanto "bonita ideia" e são, assim, parte de uma determinada maneira de se colocar frente ao mundo.

O desinteresse de Benedito por questões práticas, anunciado pelas inúmeras coleções que mantém e que pouco acrescentam ao seu dia a dia, é, finalmente, ironizado pelo narrador, que expõe o alheamento do personagem frente à questão que embasa o seu discurso de posse na câmara. Referimo-nos, aqui, à passagem final do conto, quando Inácio, antes de ouvir o discurso do futuro deputado, fala justamente sobre as estradas de ferro. $\mathrm{O}$ assunto serve,

20 BOSI, cit., p. 118. 
afinal, apenas como pretexto para que Benedito exercite o seu discurso e exiba a sua capacidade oratória.

Contei-lhe algumas particularidades técnicas [sobre estradas de ferro], que ele ouviu distraidamente, - ou porque a minha narração fosse em extremo complicada, ou por outro motivo. Quando acabei, disse-me que estimava ver-me entregue ao movimento industrial; era dele que precisávamos, e a este propósito fez-me o favor de ler o exórdio do discurso que devia proferir dali a dias. ${ }^{21}$

Vale retomar, aqui, algumas palavras de Raimundo Faoro, quando discorre sobre a política nos escritos machadianos. Para o pesquisador,

Sempre que a política irrompe numa página de Machado de Assis, direta ou indiretamente, traz, ainda que pela via da insidiosa curva, a denúncia do pecado original. Expressa um jogo irresponsável - no sentido que não responde perante outrem - dos perseguidores da glória pública. A outra glória, que está nas letras e na ciência, não basta [...]. A glória política está nas esquinas e no parlamento. É, todavia, inautêntica, postiça, representando a comédia das vaidades. ${ }^{22}$

Em certo sentido é o que vemos em "Evolução". Um jogo irresponsável governado pela vaidade, cujo fim é a glória pública. A questão que parece, por fim, pairar sobre o conto é justamente qual o tipo de mudança que homens públicos como Benedito poderiam propiciar ao país. Afinal, bonitas ideias não são sinônimo de iniciativas originais e o que vemos, nessa história de Machado, é a prática de um determinado tipo de política, em que o mais forte, para retomar Spencer, permanece sempre no topo de um processo e, no entanto, dá continuidade a certa "evolução" que nunca transforma coisa alguma.

\section{Referências}

21 ASSIS, cit., p. 207.

22 FAORO, O território da política em Machado de Assis, p. 453-454. 
ASSIS, Machado de. Evolução. Contos: uma antologia. Seleção, introdução e notas de John Gledson. São Paulo: Companhia das Letras, 2004. vol. 2, p. 201-207.

BOSI, Alfredo. Machado de Assis: O enigma do olhar. São Paulo: Ática, 2003.

FAORO, Raymundo. O território da política em Machado de Assis. Teresa - Revista de literatura brasileira 6-7. São Paulo: Ed. 34; Imprensa Oficial, 2006, p. 453-456.

ADRIANA DA COSTA TELES realizou pesquisa de pós-doutorado em Teoria da Literatura na Universidade de São Paulo. É autora do livro O labirinto enunciativo em Memorial de Aires (Annablume, 2009) e de diversos artigos publicados no Brasil e no exterior. Interesses atuais de pesquisa envolvem a presença de Shakespeare na obra de Machado de Assis. Atualmente realiza segundo estágio de pós-doutorado na Universidade de São Paulo, com bolsa Fapesp, desenvolvendo o projeto: "Romeu e Julieta nos contos de Machado de Assis: uma poética do amor e do desengano". E-mail: <driteles@ig.com.br>.

Recebido: 13.09 .14

Aprovado: 30.10.14 